\title{
The key success factors in focus group discussions with the elderly for novice researchers: a review
}

\author{
Kasorn Muijeen, Puangpaka Kongvattananon and \\ Chomchuen Somprasert \\ Faculty of Nursing, Thammasat University, Bangkok, Thailand
}

\begin{abstract}
Purpose - This study aimed to discuss the key success factors in focus group discussions among the elderly as a means of supporting novice researchers and also to share the experiences of novice researchers with focus group discussions.

Design/methodology/approach - This study used a literature review of previous studies that revealed three themes regarding the key success of focus group discussions with the elderly. Focusing on issues published between 2009 and 2019, four health-related databases, namely the Cumulative Index of Nursing and Allied Health Literature (CINAHL), ScienceDirect, PsycARTICLES and Thaijo were investigated using keyword searches, both individually and in combination, and the inclusion criteria used in selecting relevant articles as primary sources included research written in the English and Thai languages.

Findings - The literature review involved eight published articles related to this topic in the nursing field. Three themes for key successes were identified as follows: good planning and convenient organization, being accepting and flexible concerning their opinions and good management.

Originality/value - Focus group discussions with the elderly are complex and challenging for novice researchers. It is necessary that a novice researcher in the nursing field builds up the skills of a moderator in conducting focus group interviews if he or she wishes to obtain rigorous data.
\end{abstract}

Keywords Focus group discussion, Elderly, Novice researcher

Paper type Review

\section{Introduction}

Qualitative research on the elderly population requires understanding on the part of the researcher perhaps more than that required for other age groups because these members of the population have had a great deal of life experience, and some are very knowledgeable. Some, however, have not been very successful in life. This range makes focus group discussions a challenge. Collecting the qualitative research data for the present study focused on methods that were consistent with the natural way of life of people in society. In Thai society, especially in Thai villages, people often talk in groups at leisure or while carrying out activities where they can carry on a conversation at the same time. Therefore, group discussion is a normal social behavior in communities or societies that are familiar with each other. Qualitative researchers sometimes use this activity as a data collection method [1]. Focus group discussion in qualitative research refers to a data collection method that focuses on discussing and exchanging opinions and experiences with the participants. Moreover, with this method, the researcher can observe the participants' interactions with each other and talk to them, thus covering the various issues that have emerged during the conversation and using them for further analysis [2].

(C) Kasorn Muijeen, Puangpaka Kongvattananon and Chomchuen Somprasert. Published in Journal of Health Research. Published by Emerald Publishing Limited. This article is published under the Creative Commons Attribution (CC BY 4.0) license. Anyone may reproduce, distribute, translate and create derivative works of this article (for both commercial and non-commercial purposes), subject to full attribution to the original publication and authors. The full terms of this license may be seen at http:// creativecommons.org/licences/by/4.0/legalcode

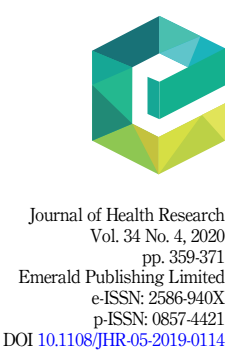


JHR 34,4

Research on the elderly in Thailand has generally focused on illness and disability. However, for the past decade, this trend has been expanded and now, "successful or healthy aging" or "healthy elderly" are issues that are discussed [3]. The increasing number of elderly people in the world has resulted in the need to study more deeply the factors that influence the health of older people [4] and perhaps especially understand why some older people seem to adapt to the challenges of the aging process whilst others cannot despite interventions and policies targeted at them. Therefore, qualitative research on the elderly is often focused on certain aspects, such as health awareness or the health literacy of the elderly [5]. Focus group discussions with the elderly, on the other hand, are a popular method of collecting data for qualitative research purposes. However, focus groups represent a challenge for new researchers in terms of collecting qualitative data. Novice researchers are typically concerned about the process of focus groups with the elderly and need to understand the characteristics of this special group. The main responsibility of the moderator in this context is to create discussions that offer useful responses got from the participants [6]. Moreover, the novice researcher needs to be aware of these factors because the focus group discussion provides a quick approach to research which may require considerable time for analysis. Careful planning regarding the moderation of focus group discussions is the basis for successful qualitative research [7] in this area. When using the discussion group method, preparation has many aspects, and effort must be made so that the time and effort will not be wasted [8].

The processes of focus group discussions with the elderly are challenging for new researchers who need previous experience on conducting such discussions or previous experience with being a moderator, all of which are a part of the data collection method in qualitative research. Addressing issues such as good planning and organizing the participants and facilities, as well as training, to understand the characteristics of being a good moderator, as well as having an accepting attitude and being flexible are key to the success of group discussions for novice researchers. In addition, several studies have shown that success in conducting focus groups mainly derives from the characteristics of an effective facilitator or moderator. In addition, training and personal readiness are essential in order to enhance the moderator's skills $[9,10]$.

This study has two main points of interest. The first is to understand the factors required in order to conduct focus group discussions amongst the elderly for novice researchers. The second is to describe the researcher's experience with others by sharing the experience of the following published project: "The Effects of Using a Knowledge-management Development Program on Knowledge Management Behaviors for the Health Promotion of Elderly Leaders in the Romyen Community in Thailand" [11]. The study's objective provides a discussion of the key success factors of focus group discussions with the elderly for novice researchers.

\section{Methods}

Selection criteria and search strategy

A systemic review was used on articles published between 2009 and 2019, using four healthrelated databases, namely the Cumulative Index of Nursing and Allied Health Literature (CINAHL), ScienceDirect, PsycARTICLES and Thaijo, which were investigated using keyword searches.

Systemic and critical reviews used the guiding framework based on the PRISMA 2009 flow diagram [12], which is composed of four steps as follows: identification, screening, eligibility, and included. From the database, 377 studies published from January 2009 to March 2019 were identified that could be adapted as a PRISMA 2009 flow diagram for the article selection process, as shown in Figure 1. The process of searching began with step 1 as follows: identification using the keywords used within the database search, both individually and in combination, including the terms "key success," "moderator," "facilitator," "conduct," "focus 

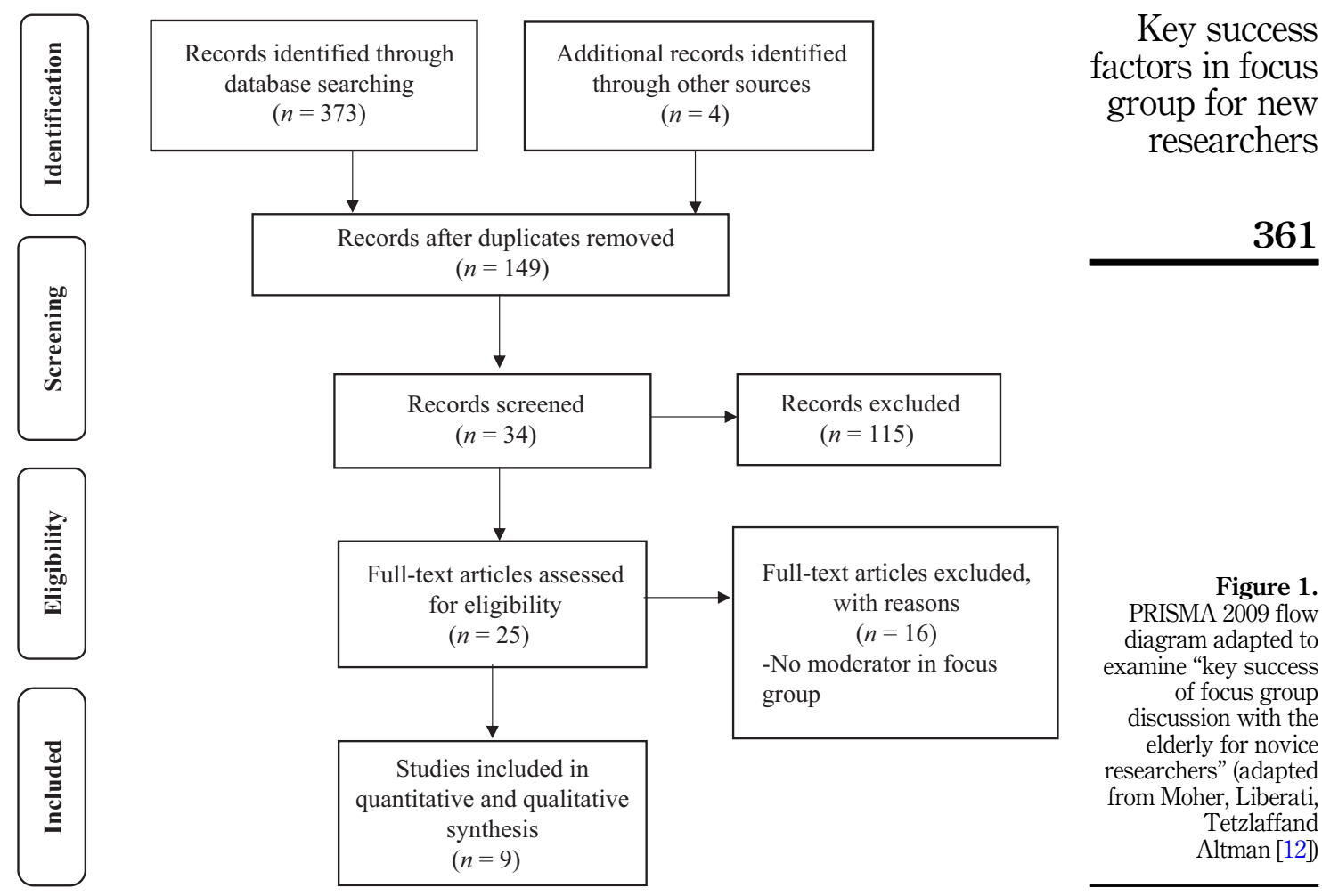

group discussion with the elderly," "focus group discussion with older adults," "novice researchers" and "experience novice researchers." Step 2 included the screening of articles from the inclusion criteria used in selecting relevant articles as primary sources. This was research written in the English and Thai languages, while the exclusion criteria were articles written in other languages and that were not related to the novice or new researcher as a moderator in focus group discussions with the elderly or focus group discussions with older individuals. Step 3 concerned eligibility, where the full text of the article was examined by checking the content or details of the investigation, as depicted in Figure 1, for a total of 25 full articles repossessed and checked for eligibility. Step 4 included twenty-five eligible articles to be considered; however, sixteen articles did not have a moderator in the focus group. Finally, the nine remaining articles were qualitative and quantitative studies synthesized by the author, as shown in Figure 1.

\section{Study selection and data extraction}

The data extracted from the studies were tabulated independently by the authors, with data including the study design, purpose and key content or findings of the studies. The findings or the key content were related to the factors connected with focus group discussions, such as the skill of the moderator and how to conduct a focus group discussion.

\section{Ethical consideration}

This study did not involve human participants but rather used a literature review of previous studies. 


\section{Results}

The main results were derived from information gathered from nine articles related to the key success factors regarding focus group discussions among the elderly with novice researchers. These nine articles were divided into two parts as follows: the first part concerned the research and literature related to focus group discussions, as can be seen in the seven articles presented in Table I; and the second part concerned research that used focus group discussion strategies with the elderly, as shown in Table II.

The main messages from each paper were presented after a thorough analysis, as seen in Tables I and II. According to the information in Table I, the study $[13,15]$ presented the steps of a focus group, including planning and good communication skills for conducting focus group discussions consistent with Doody [9], who mentioned the environment and duration of the focus group as being important factors. An effective moderator should be a good listener and possess good communication skills. Moreover, Wilson [16] described planning and the role of the moderator as being important as well. As indicated, the size of the focus group depends on the complexity of the topic and the skill of the moderator [14]. A skillful moderator needs to know the topic in depth or should be an expert in the subject of discussion [17]. Technology can also affect the focus group [18]. Table II [19, 20] supports the characteristics of the elderly participant group and how to create a successful focus group discussion. According to the data, the relevant information concerning how to successfully complete a focus group discussion with the elderly can be summarized according to three key success factors as follows: 1) Good planning and event organization, 2) Be accepting and flexible concerning their opinions and 3) Have good management skills.

\section{Good planning and event organization}

The stage of good planning and event organization includes preparation, the presession and the session itself. These are important points for novice researchers in terms of conducting a successful focus group discussion. Good planning and event organization should cover the researcher's team, the participants, the environment and question creation in line with the objectives of the focus group. The participants should be contacted in advance and be made aware of the objectives of the activity. It is important to select suitable persons for the focus group. The researcher has to give careful attention to time and provide enough time to prepare. This covers the duration of the focus group, the selection of the participants, the size of the group, preparing the environment, conducting the focus group, supporting the participants during the interview and the participants' role as a moderator. Wilson [16] recommends that the moderator reviews the literature on the topic, prepares to take field notes and prepares his or her role in advance. Questions should also be prepared in advance with the research team, considering the purpose of the study, and especially for the elderly, the questions should be relatively easy. In addition, in order to collect comparable data from all of the focus group discussion participants, a list of broad questions or predetermined probes can be developed as a guide for the moderators in order to facilitate the discussion among the participants. Some of the questions in a focus group discussion from Reichstadt's study [21] are, for example, "How would you define successful aging?" and "What are the necessary components of successful aging?" These questions can guide the moderator in conducting the group and will help him or her explore the research problem. In each focus group, the moderators can begin with these broad questions, with further questions asked based on the participants' responses, in order to elicit additional opinions from the group. This ensures that the participants are provided with an opportunity to discuss their personal attitudes and beliefs [1]. For the conclusion stage, the moderator should choose approximately five factors related to how to be successful in the focus group discussion, 


\begin{tabular}{lll}
\hline Authors & Type of article & Purpose \\
\hline Shaha et al. [13] & Literature review & To describe how to control \\
& & the institutional, \\
environmental and other \\
factors involving focus \\
groups regarding sensitive \\
topics
\end{tabular}

Key content/findings

Key success factors in focus

To assist novice qualitative researchers in preparing and planning focus groups and in developing an understanding of the process of focus groups
To present an overview of the focus group as a research tool in nursing research and particularly in nursing education
The steps of a focus group, including planning and conducting data analysis. The moderator must gain the trust of the participants and know the topic in depth so as to lead the focus group discussion efficiently. Furthermore, it is important for the moderator to encourage all participants to respond; thus, he or she should be able to lead with good communication skills

\section{group for new researchers}

363

The moderator should create a relaxed and friendly atmosphere as well as a comfortable environment when conducting a focus group interview. The duration of an interview depends on the complexity of the topic. It usually lasts 1 to $2 \mathrm{hrs}$. The questions should be open-ended, and the moderator should avoid asking emotionally troubling questions. In order to conduct a focus group interview, an effective moderator should be a good listener and possess good communication skills

The focus group should contain participants from homogeneous backgrounds because they may influence the group discussion.

However, some moderators include participants from heterogeneous backgrounds for exploratory purposes. The group size depends on the complexity of the topic and the skill of the moderator. It is suggested that an appropriate group size ranges from 4 to 12 participants. For the optimal use of the group, the best number seems to be 4 to 6 people
Table I.

Research or literature related to focus group discussions 


\begin{tabular}{lll}
\hline Authors & Type of article & Purpose \\
\hline O'Connor and & Discussion paper & $\begin{array}{l}\text { To describe how a novice } \\
\text { researcher can conduct a } \\
\text { Murphy [15] }\end{array}$ \\
& & focus group interview
\end{tabular}

Key content/findings

\section{4}

Wilson et al. [16] Discussion paper

$\begin{array}{ll}\text { Pawi et al. [17] } & \begin{array}{l}\text { From website } \\ \text { www.researchgate.net }\end{array}\end{array}$

Stancanelli [18] Discussion paper
To describe how the novice researcher can conduct a focus group interview that produces insightful information

To discuss the challenges in conducting a focus group interview

To describe the process of online focus groups, requiring the researcher to search into the literature on traditional focus groups because an understanding of traditional groups is a basic part of the online focus group process
During the planning process, in order to create a safe environment, the moderator should prepare a quiet room. Light refreshments are also served to all participants as incentives and for creating a friendly atmosphere. The challenges found were (1) the interference of sounds during the interview recording, and (2) the preparation of the field notetaker

During the planning stage, the moderator reviews the literature on the topic, prepares to take field notes and practices the role of moderator. It is important to keep the atmosphere relaxing, comfortable and non-judgmental. This will help the participants feel safe in presenting their opinions and experiences. The success in conducting a focus group also depends on good teamwork between the moderator and the assistant, if any

A skillful moderator needs to know the topic in depth or should be an expert in the subject of discussion. It is also important for the moderator to encourage all participants to respond Technological advances continue to affect qualitative research, especially regarding the appointment of sample groups, for creating focus group discussions. In addition, many methods in the practice of the data collection have been enhanced through technology, for example using digital cameras, video recorders and transcription software. These are materials that can be used in focus group discussions

Table I. 


\begin{tabular}{|c|c|c|c|c|}
\hline Authors & $\begin{array}{l}\text { Type of } \\
\text { article }\end{array}$ & Purpose & Key content/findings & $\begin{array}{l}\text { Key success } \\
\text { factors in focus }\end{array}$ \\
\hline \multirow[t]{2}{*}{ Gray et al. [19] } & \multirow[t]{2}{*}{$\begin{array}{l}\text { Discussion } \\
\text { paper }\end{array}$} & \multirow[t]{2}{*}{$\begin{array}{l}\text { To explore how Thai people } \\
\text { define "older persons" and what } \\
\text { perceived psychosocial and } \\
\text { health impacts may occur if the } \\
\text { idea of an "older person" is } \\
\text { redefined }\end{array}$} & \multirow{2}{*}{$\begin{array}{l}\text { The perceived current definition of } \\
\text { "older persons" is those aged } 60 \\
\text { and older, and this carries with it } \\
\text { both negative and positive } \\
\text { connotations. Most participants } \\
\text { felt that it would be appropriate to } \\
\text { consider a revised definition of an } \\
\text { "older person" if the following } \\
\text { criteria were taken into } \\
\text { consideration: (1) chronological } \\
\text { age only but raising the age to } 65 \\
\text { or } 70 ;(2) \text { chronological age and } \\
\text { positive attributes (3) positive } \\
\text { attributes only and (4) no criteria } \\
\text { at all }\end{array}$} & $\begin{array}{l}\text { group lor new } \\
\text { researchers }\end{array}$ \\
\hline & & & & \\
\hline $\begin{array}{l}\text { Sutipan and } \\
\text { Intarakamhang [20] }\end{array}$ & $\begin{array}{l}\text { Discussion } \\
\text { paper }\end{array}$ & $\begin{array}{l}\text { To identify the healthy lifestyle } \\
\text { needs of hypertensive elderly and } \\
\text { to explore the barriers and } \\
\text { facilitators associated with } \\
\text { healthy lifestyle behaviors }\end{array}$ & $\begin{array}{l}\text { Participants identified barriers } \\
\text { that included a lack of healthcare } \\
\text { concerns, a lack of motivation, } \\
\text { their perceived poor physical and } \\
\text { mental health and inadequate } \\
\text { community resources. Facilitators } \\
\text { possessing knowledge of } \\
\text { hypertension, as well as relevant } \\
\text { family support, were also } \\
\text { identified. The findings are } \\
\text { thought to be useful in terms of the } \\
\text { planning and development of an } \\
\text { effectively tailored program to } \\
\text { promote healthy lifestyle behavior } \\
\text { (HLB) }\end{array}$ & $\begin{array}{r}\text { Table II. } \\
\text { Research on focus } \\
\text { group discussions with } \\
\text { the elderly }\end{array}$ \\
\hline
\end{tabular}

including the size of the focus group, the timing, the environment and location, the selection of participants and understanding the participants and focus group scripts and materials.

Size of the focus group

Variations exist in the literature regarding the optimum size of a focus group, depending on the complexity of the topic, the type of participants and the skills of the moderator. Most researchers suggest that the appropriate group size ranges from 4 to 12 participants $[1,2,6]$. A large group can generate more opinions and/or feelings about the topic, while a smaller group may be more beneficial when sensitive issues are concerned. Moreover, the number of participants in the focus group can depend on the participants having the same experience because some experiences take a long time to discuss and, for this reason, the group should be a small group [22]. Therefore, the size of a focus group can vary according to the research objective, can be flexible and should be large enough to create a group discussion. For example, most focus group discussions with the elderly in Thailand have 6-12 participants [19-21].

\section{Time of the focus group}

The period of time for conducting the focus group depends on the complexity of the topic, the number of questions asked and the size of the group. The duration of the focus group 
JHR 34,4

discussion should be in the range of 1 to $2 \mathrm{hrs}$ and should not be longer than $2 \mathrm{hrs}$ because this can affect the physical and mental health of the participants, especially among the elderly, who often have problems with their physical health and are tired from the effects of old age [21]. Barbour [2] recommends that the time for discussion be limited to 45 to 90 mins because outside this time period, the participants may lose their ideas and thoughts about the topic, or the session time would have been reached. However, a period of less than $1 \mathrm{hr}$ may prevent the discussion of important issues in accordance with the research objectives. Therefore, it is recommended to use a flexible time period of one hr to no more than $2 \mathrm{hrs}$.

\section{The environment and location}

The environment and location are important as they can have a significant impact on the discussion of a focus group. The following have been suggested concerning the environment and location of a focus group discussion among the elderly: (1) the room should be of adequate size, lighting and temperature; (2) the seating should be arranged in a circle format to ensure that all the participants can see one another, and the ergonomic characteristics of the elderly should be considered; for example, chairs should not be too high or too low because most older people have problems with their knees; (3) the moderator should create a relaxing atmosphere, comfortable and nonthreatening, and the participants should not feel that the questions are too abstract, for example using academic language and (4) the location or setting should be a safe environment where disturbances from other people or external noise $[14,15]$ are not present.

\section{Selection of participants and understanding the participants}

The groups can be homogeneous or heterogeneous, depending upon the purpose of the research; yet, attendees should have previous experience or prior knowledge of the topic. Homogeneous groups have similar characteristics, such as being from the same background, being close to the same age, of the same gender, social status or occupation and having experience with the topic as these factors may influence the group discussion. However, heterogeneous groups could be used for exploratory purposes where varieties of groups are preferred. Moreover, it is important to make sure that the focus group participants are not in conflict with one another or are incompatible. Pawi [17], for example, discussed the differences in the research outcomes obtained from homogeneous and heterogeneous groups, as well as the differences between groups of individuals that were familiar with each other or intimate and those that were strangers. Therefore, novice researchers need to understand all of the steps of the focus group discussion. The novice researcher should carefully select the participants in the group because this will help him or her achieve the research objectives and make it easier to control the focus group discussion. In the Thai context, the novice researcher can use respectful pronouns instead of calling people by their proper names, such as uncle and aunt, when they conduct a group. In addition, the novice researcher must try to find out which of the elderly participants have hearing problems, and while he or she is moderating a focus group discussion his or her speaking volume must not be too loud or too low, and questions may have to be repeated $[19,20]$.

\section{Focus group scripts and materials}

Nagle and Williams [22] stated that the lack of important equipment or materials could interrupt or even stop the discussion from flowing smoothly, causing participants to feel uncomfortable and limiting the discussion. The moderator could prepare a script as an outline for the focus group discussion. The scripts for introducing the group discussion can include, for example, the following: (1) welcoming statements, including the process of self- 
introduction and group member introductions, with members providing general stories about themselves; (2) overviewing the topic; they can begin by explaining the purpose of the study and of the focus group; (3) stating the ground rules, reviewing the group discussion rules and other information that the participants need to know prior to the group interview and (4) beginning with the first question. It is also important that the questions in the scripts move from the general to the more specific or in order of importance. The research team should brainstorm in order to develop a list of questions based on the purposes of the research. These should be open-ended rather than yes-no questions, to generate more useful information from the group discussion.

O'Connor and Murphy [15] suggested that creating focus groups for the elderly has nine components that help to complete the group, which can be summarized as follows: (1) audiotapes or audio cassettes used to record the data; (2) participant information form and consent form; (3) labels for the participants and moderators; (4) a watch (5) coffee and bakery goods or drinks; (6) a sign-in consent form and a document listing the participants; (7) flip charts and markers and (8) notebooks, pens and audio cassettes that can be used for recording the data. Digital voice recorders are important because recording focus group discussions is not easy. Focus groups are notoriously difficult to manage and control, especially amongst the elderly, who may speak softly, which makes for poor recording [18].

\section{Being accepting and flexible concerning their opinions}

By recognizing the importance of the moderator role, the novice researcher should gain insight into the requirements of this role in order to promote his or her effectiveness. One's life and work experience may provide a level of preparation, but the development of additional skills can be carried out with the following: theoretical knowledge practice using open-ended questions and rewriting; being familiar with many group conversations; conducting a pilot study; talking to researchers that have had experience in using group discussion methods and participation in focus group discussions for the purpose of critical analysis. A novice researcher should understand that teamwork is important, and various techniques can be used to help solve the problems that may arise during the decision-making process because it is difficult for only one person to manage and conduct a complete focus group. Conducting a focus group is difficult for a novice researcher, especially regarding the data collection and the work process of the focus group. Accepting comments and being flexible are the challenges for moderators to improve their skills, including the following; good interpersonal skills, being good listeners and being non-judgmental and adaptable.

\section{Good interpersonal skills}

The interpersonal skills of the moderator are crucial to success in conducting a focus group. Shaha et al. [13] agree that interpersonal and group leadership skills are essential. At the beginning of the group interview, a moderator welcomes all participants and introduces himself or herself and the team. He or she then requests the participants to introduce themselves and to put on a name label. Then, he or she identifies the purpose of the interview, asks an introductory question as a warm-up to create a relaxing atmosphere and thanks them afterward for sharing their experience. Moreover, Krueger and Casey suggest that light refreshments and eating together tend to promote conversation, discussion and communication within the focus group. Nagle and Williams [22] suggest that the communication skills of the moderator also involve how to deal with interruptions when someone is providing an opinion. In this regard, the moderator should provide some signals for them to wait, explaining that they will be given an opportunity to speak next. In Thailand, most focus group discussions with the elderly are significant because of research carried out by the moderator and his or her relationship with the group [20]. If the relationship between 
JHR 34,4

368

the group participants and the moderator is good, insightful information can be received and the research questions can be answered. On the other hand, if the relationship is not good at the outset, the group operation will have obstacles.

\section{Being good listeners}

A moderator must be a good listener and a thinker at the same time. Curtis and Redmond [23] stated that a moderator is required to concentrate on the discussion and to observe the level of the participants' interaction during a group discussion. Packer-Muti [10] suggested that a moderator should listen attentively with sensitivity and empathy, and Mack et al. [24] pointed out the importance of reading the body language of the participants, including crying, which can be related to the content of the discussion, in which case the moderator must not join in the emotion or outwardly express sympathy. In addition, the moderators must listen intently while engaging with the other participants, without expressing emotions themselves. If a problem occurs in a dynamic group, the group of responders will respond accordingly, with the moderator warning the participants about the rules of participation in the focus group. However, the important thing to consider is that the participants are elderly and when they speak the moderator must actively listen.

\section{Be non-judgmental and adaptable}

The moderator must accept that the participants may be inclined to divert from the expected answers or thought patterns, in response to questions. Mack et al. [24] mentioned that a moderator should believe that all participants have ideas on the topic and that the moderator should be impartial with his or her general opinions. Nagle and Williams [22] recommend that a moderator avoid head nods or responses such as "yes," "I agree" and "OK." These responses convey acceptance of the answers, which can limit the findings and/or any new ideas or opinions that may come later from other participants in a group. A good moderator needs to have an adaptable and non-judgmental attitude with no partiality or bias toward any of the group participants.

\section{Good management of group dynamics}

During a focus group, the researcher recognizes the potential tension between participants with certain characteristics or attitudes. Unfortunately, occasionally, group dynamics cannot be identified at the beginning of a session. The moderator plays the important role of the manager in creating the appropriate group process in which all the participants can participate in the discussion and exchange ideas. However, some group dynamics cannot be predicted. There have been many suggestions for moderators concerning how to deal with disruptive group dynamics, such as countering dominating or disruptive group members and concerning shy or silent participants. However, the researcher's experience will help to resolve problems with disruptive members or barriers in the group dynamics. This study provides details of the experience of novice researchers in the implementation of focus group discussions for the elderly, as detailed below.

\section{The experience of novice researchers in focus groups for the elderly}

This section of the present paper explains theresearcher's experience with other researchers by sharing her direct experience from the project mentioned above. The feeling of the author during the first focus group amongst the elderly was one of excitement. The author strongly agrees that good planning and convenient event organization, being accepting and flexible and practicing good management of the group's dynamics are important factors to make the focus group a success for new researchers. However, in conducting that focus group, where 
the elderly expressed all of their opinions, the data were still incomplete in relation to the objectives, which will be discussed in greater detail in the next section.

\section{Discussion}

As Thai society is developing into an aging population, the elderly population is an important group. Therefore, there has been a great deal of education about elderly groups, and it can be said that qualitative research has allowed researchers to find answers concerning the elderly in profound ways. Based on the literature review and the shared experiences of the author in conducting focus groups with the elderly, it can be concluded that the keys to success include all of the three steps discussed above because they represent the sequence of events that will occur in focus group discussions.

Good planning and convenient event organization represent the preparation process, and these are important for a successful group discussion. The experience of the author in the research project mentioned above can be described as follows: the size of the group from this research comprised five elderly participants in a homogenous group of females who had the same experience with knowledge management training projects. It was concluded that the research team should meet and prepare itself before beginning the focus group, including reading about and understanding the research objectives and sharing the duties for preparation in various steps $[14,20]$.

The skill of being a good listener and being non-judgmental needs to be practiced, and more experience in conducting focus groups is required [20,21]. The experience of this author could provide an example of the skills of the moderator and suggests that creating a focus group with the elderly also requires building relationships rather than just using friendly questions. Moreover, being a good listener and being non-judgmental and adaptable are important examples from the author's experience, and the moderator would be advised to be a quick decision-maker, especially when the participants talk too much. The moderator should make conclusions and lead to the next topic, and he/she should invite other participants to share their opinions. An example can be seen in the words of a participant: "You must try to eat lemon when you wake up the morning; it will be good for the digestive system." The moderator concluded the conversation as follows: "You think that lemons are good for the digestive system. The other participants agree or disagree? Why?" Good management of group dynamics is consistent with the role of the moderator $[16,19]$.

In addition, the popularity of the Internet and technology including online or Facebook can facilitate the process of focus group discussions. For example, the researcher can use online methods or Facebook to make an appointment with the participants [25]. Some studies [18, 26] have mentioned the benefits of new approaches, such as the use of online focus groups that give individuals that are difficult to reach the ability to participate and that give researchers access to a greater variety of participants. However, there are still limitations in using technology for the elderly in terms of preparing focus groups [27]. The novice researcher should be careful about using technology with elderly sample groups because they are often limited in their ability in using the Internet and technology.

\section{Conclusion}

Focus group discussions with the elderly are complex and challenging for novice researchers, and a variety of skills are required when conducting a focus group. Therefore, the novice qualitative researcher needs to have confidence in the skills discussed in this paper so that he or she can obtain rigorous data. A novice researcher should also understand the strengths and limitations of a focus group discussion with the elderly, as this can have an impact on how to lead the group in order to generate quality data.
Key success factors in focus group for new researchers

369 
JHR

34,4

\section{References}

1. Stalmeijer RE, McNaughton N, Van Mook WN. Using focus groups in medical education research: AMEEguide no. 91. Med Teacher. 2014 Nov; 36(11): 923-39, doi: 10.3109/0142159x.2014.917165.

2. Barbour RS. Focus groups. In: Bourgeault I, Dingwall R, de Vries R, editors.The SAGE handbook of qualitative methods in health research. Los Angeles: Sage; 2010. 327-52.

3. Kinsella KG, Velkoff VA. An aging world: 2001, Washington, DC: US Government Printing Office; 2001.

4. World Health Organization [WHO]. Ageing and health.[updated 2018 Feb 5; cited 2019 April 1]. Available from: https://www.who.int/news-room/fact-sheets/detail/ageing-and-health.

5. Dilshad RM, Latif MI. Focus group interview as a tool for qualitative research: an analysis. Pakistan J Soc Sci. 2013; 33(1): 191-8.

6. Webb C, Doman M. Conducting focus groups: experiences from nursing research. Junctures J Themat Dialogue. 2008; 10: 51-60. [cited 2019 April 1]. Available from: https://junctures.org/index. php/junctures/article/view/49/394.

7. Kidd PS, Parshall MB. Getting the focus and the group: enhancing analytical rigor in focus group research. Qual Health Res. 2000 May; 10(3): 293-308, doi: 10.1177/104973200129118453.

8. Jamieson L, Williams LM. Focus group methodology: explanatory notes for the novice nurse researcher. Contemp Nurs. 2003 Jun; 14(3): 271-80, doi: 10.5172/conu.14.3.271.

9. Doody O, Slevin E, Taggart L. Preparing for and conducting focus groups in nursing research: part 2. Br J Nurs. 2013 Feb; 22(3): 170-3, doi: 10.12968/bjon.2013.22.3.170.

10. Packer-Muti B. Conducting a focus group. Qual Rep. 2010; 15(4): 1023-6.

11. Othaganont $\mathrm{P}$, Kongvattananon $\mathrm{P}$. The effects of using a knowledge management development program on knowledge management behaviors for the health promotion of elderly leaders in the Romyen community: research project. Pathumthani: Faculty of Nursing, Thammasat University; 2018.

12. Moher D, Liberati A, Tetzlaff J, Altman DG. Preferred reporting items for systematic reviews and meta-analyses: the PRISMA statement. PLoS Med. 2009 Jul; 6(7): e1000097. doi: 10.1371/journal. pmed.1000097.

13. Shaha M, Wenzel J, Hill EE. Planning and conducting focus group research with nurses. Nurse Res. 2011; 18(2): 77-87, doi: 10.7748/nr2011.01.18.2.77.c8286.

14. Jayasekara RS. Focus groups in nursing research: methodological perspectives. Nurs.Outlook. 2012 Nov-Dec; 60(6): 411-6, doi: 10.1016/j.outlook.2012.02.001.

15. O'Connor C, Murphy S. Novice researchers' reflection on conducting a focus group. J PerioperPract. 2009 May; 19(5): 143-7, doi: 10.1177/175045890901900504.

16. Wilson R, Slaughter SE, Forbes D, Hanson HM, Khadaroo RG. Experiences of a novice researcher conducting focus group interviews. International Journal of Nursing Student Scholarship. 2016; 3: $1-11$.

17. Pawi Putit Z, Buncuan J. Challenges in conducting focus group: moderators' experiences in Nursing. Journal of Malaysia Nurses Association. 2010; 5: 2-9.

18. Stancanelli J. Conducting an online focus group. Qual Rep. 2010; 15(3): 761-5.

19. Gray RS, Pattaravanich U, Chamchan C, Prasartkul P. Perceived negative and positive impacts of redefining older persons in Thailand. Journal of Population and Social Studies. 2015; 23(1): 73-85.

20. Sutipan P, Intarakamhang U. Healthy lifestyle behavioral needs among the elderly with hypertension in Chiang Mai, Thailand, International Journal of Behavioral Science. 2017; 12(1): 1-2.

21. Reichstadt J, Depp CA, Palinkas LA, Folsom DP, Jeste DV. Building blocks of successful aging: a focus group study of older adults' perceived contributors to successful aging. Am J Geriatr Psychiatry, 2007 Mar; 15(3): 194-201, doi: 10.1097/JGP.0b013e318030255f. 
22. Nagle B, Williams N. Methodology brief: introduction to the focus group. Center for Assessment, Planning and Accountability; 2013. [cited 2019 April 2]. Available from: http://www.mmgconnect. $\mathrm{com} /$ projects/userfiles/file/focusgroupbrief.pdf.

23. Curtis E, Redmond R. Focus groups in nursing research, Nurse Res. 2007; 14(2): 25-37, doi: 10.7748/ nr2007.01.14.2.25.c6019.

Key success factors in focus group for new researchers

24. Mack N, Woodsong C, MacQueen KM, Guest G and Namey E. Qualitative research methods: a data collector's field guide. North Carolina, US: Family Health International; 2005.

25. Watson M, Peacock S, Jones D. The analysis of interaction in online focus groups. Int J TherRehabil. 2006; 13(12): 551-7, doi: 10.12968/ijtr.2006.13.12.22471.

26. Woodyatt CR, Finneran CA, Stephenson R. In-person versus online focus group discussions: a comparative analysis of data quality. Qual Health Res. 2016 May; 26(6): 741-9, doi: 10.1177/ 1049732316631510.

27. Thrul J, Belohlavek A, Hambrick D, Kaur M, Ramo DE. Conducting online focus groups on Facebook to inform health behavior change interventions: two case studies and lessons learned. Internet Interv. 2017 Sep; 9: 106-11, doi: 10.1016/j.invent.2017.07.005.

\section{Corresponding author}

Puangpaka Kongvattananon can be contacted at: puangpaka@nurse.tu.ac.th

For instructions on how to order reprints of this article, please visit our website: 